\title{
Review: The pre-pubertal bovine mammary gland: unlocking the potential of the future herd
}

\author{
A. J. Geiger ๑ \\ Research and Nutritional Services Department, Zinpro Corporation, Eden Prairie, MN 55355, USA
}

(Received 24 October 2018; Accepted 16 April 2019)

\begin{abstract}
Historically, pre-pubertal development of the bovine mammary gland (MG) has received little attention compared to later development. Recent evidence suggests not only that this period represents a very active time in the development of the MG but also that the first 90 days of life can partially dictate future productivity of the lactating cow. The MG, often considered quiescent during early life (first 3 months), is now known to increase in size by over 60-fold in the same period. The importance of sex steroids in MG development is well classified, but a complex signaling network exists among estrogen, progesterone and other growth factors and hormones. Complicating our understanding of this developmental period further is the discovery that preweaning nutrition of the calf not only influences the growth of the mammary parenchyma but may also alter the way in which it responds to mammogenic stimuli. Recent data suggest that feeding calves a higher plane of nutrition improves the ability of the mammary epithelium to respond to estradiol and also alters the way in which the mammary parenchyma and fat pad communicate. It is clear that early life nutrition, although able to influence the $M G$, is still poorly understood mechanistically. For example, additional evidence suggests that increased feeding rates in early life alter the morphology of myoepithelial cells in the mammary epithelium. Further data have also suggested a role for other cell types, such as immune cells, in the penetration of the mammary parenchyma into the fat pad during the early life development of the MG suggesting that mammary development is not only controlled by the local tissue population (parenchyma and fat pad) but perhaps systemically by other tissue types (i.e., immune system). Understanding the roles of these various stimuli and signaling pathways as they relate to the development of the MG in early life may hold the key to unlocking the potential for the optimal development of this crucial organ and, in turn, may lead to improvements in other phases of mammary development and milk yield potential.
\end{abstract}

Keywords parenchyma, estrogen, mammary, dairy, calf

\section{Implications}

Understanding the factors that impact milk yield in dairy animals is very important. We know that when we feed calves better they make more milk as cows, but we do not know why. Recent work from our lab uncovers part of this reason. The information presented will help us to understand how we can feed a young heifer calf to make her more productive as a cow. This will yield greater returns on investment for producers and help us create more milk for an increasing world population.

\section{Introduction}

Mammary biologists have often wondered which periods of bovine mammary development are most impactful or

E-mail: ageiger@zinpro.com represent the biggest potential carry-over effect in terms of future lactation potential. A vast majority of previous work has focused on the development of the mammary gland (MG) near the end of gestation and into lactation. Additionally, previous work has shown that pre-pubertal MG development can be negatively influenced by management factors (feeding rate, etc.; Capuco and Akers, 2010). However, more recent work has indicated that the traditional allometric phase of MG growth as defined by Tucker (2000) actually begins from birth, a time during which the MG can grow by greater than 60-fold and the body essentially doubles in size (Capuco and Akers, 2010). This realization has ignited a massive undertaking by mammary biologists and nutritionists worldwide to understand what may impact this incredibly active period of development within the bovine MG.

A summary of all work dedicated to early life mammary development is outside the scope of this review, but it has become quite clear that the MG tissue created within the 
Pre-pubertal bovine mammary development

pre-weaning period provides at the very least a foundation for subsequent MG growth, which may dictate, to some extent, the success of lactation. However, a brief discussion of the history in this area of research is warranted.

Multiple studies over the last half century have looked at the way in which dairy replacements are raised, and how future lactation performance may be impacted. Many of these studies did not focus on the MG, and some of the studies conducted in this time were not 'true' mammary biology studies. However, many studies in nutrition, etc., added to the body of work that is now used to explain the impacts of early life management decisions on future milk yield potential. The basis of these studies began with the goal of shortening the time from birth to first calving. Dairy heifers have a roughly 2-year non-productive period where no return on investment is made unless the heifer is sold. The idea was to shorten this period by encouraging a younger age at first calving. In order for first parturition to occur earlier, earlier breeding and thus earlier attainment of puberty must also occur. Puberty is highly correlated with BW (Sejrsen, 1994); thus, the most practical way to decrease the age at first calving is to stimulate faster growth rates in early life to achieve pubertal BW at a younger age. But, as mentioned, it has been well documented that accelerating gains during the entire pre-pubertal period decrease the first lactation performance (Sejrsen and Purup, 1997; Zanton and Heinrichs, 2005). Reasons for decreases in first lactation performance associated with higher pre-pubertal BW gains are still debated to some extent, but a common theme is an increase in mammary fat pad (MFP) mass accompanied with excessive pre-pubertal weight gain that impedes the development of the parenchymal (PAR) tissue. This increase in lipid accumulation is considered to be 'non-productive' in nature, and an increase in the proportion of the gland occupied by the MFP would come at the expense of the more productive, PAR tissue. Additionally, exhaustive studies conducted by Meyer et al. (2006a, 2006b) provided evidence that when pre-pubertal BW gains are excessive, the traditional allometric growth window is shortened, which limits udder development during this time.

Although it has been generally accepted that accelerated BW gain during pre-puberty has a detrimental impact on future milk yield, first lactation performance may benefit from high rates of BW gain during the early periods of life ( $<3$ months of age; pre-weaning period; milk-fed stage), as recently summarized by Khan et al. (2011). The other well-referenced work (Soberon et al., 2012) further discussed the positive impacts of greater BW gains in early life on future milk yield potential. Our lab and others (Geiger et al., 2016a; Soberon and Van Amburgh, 2017; Figure 1) have shown that enhanced feeding of calves during the milk-fed stage can increase mammary parenchyma growth both in terms of raw mass and also on a per BW basis. These findings conflict with previously mentioned data regarding the entire prepubertal period of life (period of time from birth until estrus is attained) in the dairy heifer, and at the very least, indicate how much we have left to learn about this unique organ.
The goal of this review is to discuss known factors that impact the development of the pre-pubertal MG, which have a heavy influence on early life nutritional management.

\section{The influence of hormones on the development of the bovine mammary gland}

At its basis, the MG is an accessory reproductive organ. The MGs are compound, tubulo-alveolar skin glands located on the ventral surface of the animal, and this organ's growth is subject to the heavy influence of various hormones and growth factors. This results in a complicated communication network across multiple pathways that participate in a 'crosstalk' to ultimately control the development of the MG. These concepts have been reviewed previously (Sejrsen and Purup, 1997; Purup et al., 2000; Vestergaard et al., 2003). Alterations in feeding rate of replacements, as well as dietary changes, have been shown to result in changes in circulating growth hormone (GH), insulin-like growth factor (IGF) -I, and IGF binding proteins that undoubtedly affect the activity of the MG both through local and systemic influences (Akers et al., 2000). Our lab has also conducted a host of studies using the ovariectomy (OVX) model to assess the impact of endocrine ablation on MG development. In all of these studies, the OVX procedure occurred well before the attainment of puberty. Perhaps the most important findings from these studies are that the earlier the OVX procedure occurs, the greater the negative impact on MG development is (Berry et al., 2003; Velayudhan et al., 2012). This indicates that MG development, as would be anticipated, is heavily reliant on sex steroids produced in the ovary and that this influence begins very early in life. Similar to increased nutrient intake, local MG tissue IGF-I production is reduced and the production/ secretion of IGF-I binding proteins is increased when an OVX procedure occurs (Berry et al., 2003). A reduction in cellular proliferation in the MG epithelium is also observed following an OVX (Purup et al., 1993, 1995). Of high interest is the fact that $\mathrm{GH}$ is unable to stimulate MG growth in OVX heifers, further supporting the idea of a complex network of communication responsible for MG development (Purup et al., 1995). It has been known for some time that IGF-I is critical to the early MG development, which is supported by observed increases in cellular proliferation in MG explants when IGF-I is added. However, a decrease in sensitivity to IGF-I is observed in MG explants collected from OVX heifers. In all of this, it should be noted that circulating levels of estradiol in young heifers appear to be relatively stable following an OVX procedure (Purup et al., 1993; Velayudhan et al., 2015).

The IGF-I/GH axis is merely one participant in the processes that control MG development. Older work has shown that estradiol stimulates MG growth (Woodward et al., 1993; Ellis et al., 1998), and this response is increased in a dosedependent manner (Purup et al., 1993). However, Capuco et al. (2002) provided evidence that proliferating bovine mammary epithelial cells do not express estrogen receptor- $\alpha$ $(E R-\alpha)$, the primary isotype of the estrogen receptor (ER) in 


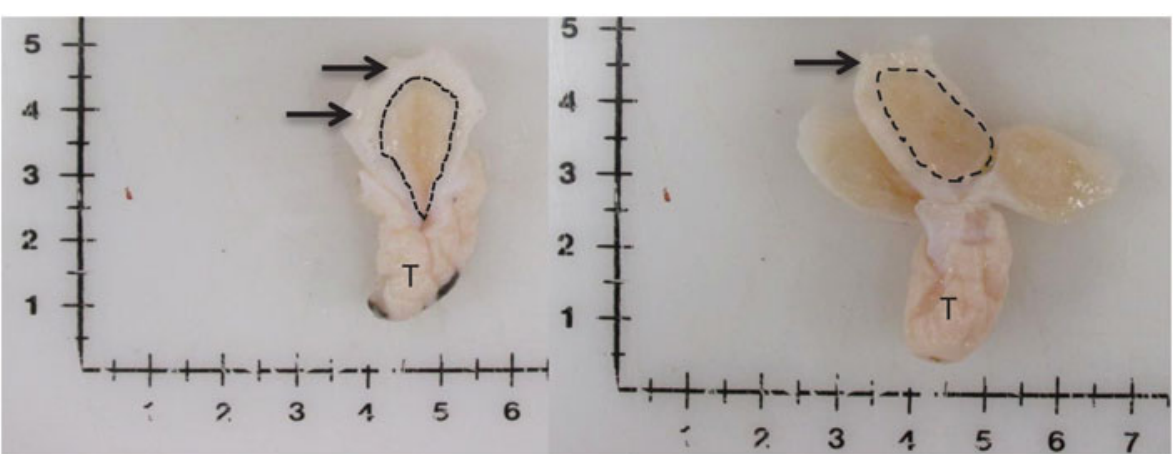

Figure 1 Visual depiction of mammary gland parenchyma development differences between calves fed a low plane of nutrition (left; $20 \%$ protein and $20 \%$ fat milk replacer) or a high plane of nutrition (right; $28 \%$ protein and $25 \%$ fat milk replacer). Arrows indicate the MFP and the light brown tissue within the dotted line indicates mammary parenchyma. This represents over a seven-fold increase in PAR mass (Geiger et al., 2016b).

the MG. This would suggest that estrogen does not have a direct effect on the proliferating mammary epithelium but, rather, is utilized locally by other tissues and cell types, triggering local tissue mediators that are more directly responsible for stimulating cellular proliferation in the MG. One hypothesis is that estrogen produced in the ovary acts on cells within the neighboring epithelium and stroma, which results in an increase in IGF-I production leading to greater PAR proliferation. However, given the nature of the MG, this is, if true, undoubtedly only a small aspect of the cross-talk occurring. Evidence for this exists in the work conducted by $\mathrm{Li}$ and Capuco (2008), where 1016 genes in the MG (common genes to both PAR and MFP) were influenced when estrogen was administered to heifers.

Aside from estrogen, progesterone is also produced in the ovary and thought to influence the development of the MG. While estrogen is thought to be heavily important in the early stages of MG development, progesterone has been suggested to play a role later in life when lobulo-alveolar development occurs. Progesterone receptors are present in the pre-pubertal bovine MG, but interestingly enough, they become undetectable following an OVX procedure (Velayudhan et al., 2015). Previous work has shown that treatment of mammary cells from heifers with progesterone alone did not have a significant impact on cellular proliferation (Woodward et al., 1993), whereas a much more favorable result was observed when estrogen and progesterone were administered in concert. Since the removal of the ovary via OVX undoubtedly has a complex impact on the animal, the ability to assess the impact of removal of one mammogenic stimulus is desirable. One such option to do so is by injecting calves with tamoxifen, an antiestrogen, to assess the impacts of only blocking the action of estrogen on the MG (Tucker et al., 2016b). Similar to the impacts of an OVX procedure, calves treated with tamoxifen (Tucker et al., 2016b; treated from 28 to 120 days of life) experienced a decrease in overall mammary PAR growth. Of particular interest was that tamoxifen-treated calves had more proliferating cells (measured via Ki67 labeling) at 120 days of age. The percentage or location of cells expressing the ER $\alpha$ or the progesterone receptor was not impacted by treatment, but ER $\alpha$-positive cells expressed ER $\alpha$ with a 6.2-fold lower intensity. A similar result was observed for the degree of progesterone receptor expression in OVX calves (Velayudhan et al., 2015). To the best of our knowledge, our lab is the first to gauge intensity of expression of steroid receptors in the MG epithelium using this technique.

\section{The influence of early life nutrition on the development of the bovine mammary gland}

With the understanding that the bovine MG is more active in the first 3 months of life than previously understood (Capuco and Akers, 2010), our lab sought to impact how plane of nutrition in early life may influence the development of this organ. The concept of influencing future milk yield and/or MG development via nutrition in early life became popular roughly a decade ago (Soberon et al., 2012). This review serves as the first complete summation of our work to this point (methods, etc., more thoroughly explained in Geiger et al., 2016b). The overarching hypothesis of this work was that plane of nutrition positively influences the growth of the calf and the developing MG through a developmental programming mechanism, wherein the neonatal, bovine MG epithelium is 'primed' to respond to mammogenic stimuli already present in the body (i.e., higher plane of nutrition (HPN) increases the efficiency with which the MG epithelium utilizes biologically normal levels of circulating estrogen). In this work, heifer calves ( $<1$ week old) were fed either a 20\% protein, $20 \%$ fat milk replacer ( $0.35 \mathrm{~kg}$ powder/day) or $28 \%$ protein, $25 \%$ fat milk replacer ( $1.13 \mathrm{~kg}$ powder/day) for 8 weeks. A portion of calves on study were harvested at weaning (8 weeks), and half of the remaining calves from each diet were given estrogen for 2 weeks to assess responsiveness to mammogenic stimuli. We hypothesized that calves fed a HPN would experience greater MG development in early life and that these calves would respond with greater magnitude to estrogen.

The impact of the above-mentioned treatments was greater than expected. At weaning, calves fed on a HPN were over $20 \mathrm{~kg}$ heavier with no negative impacts on health observed (Figure 2; Geiger et al., 2016b). Additionally, mammary PAR weights were increased by roughly seven-fold 


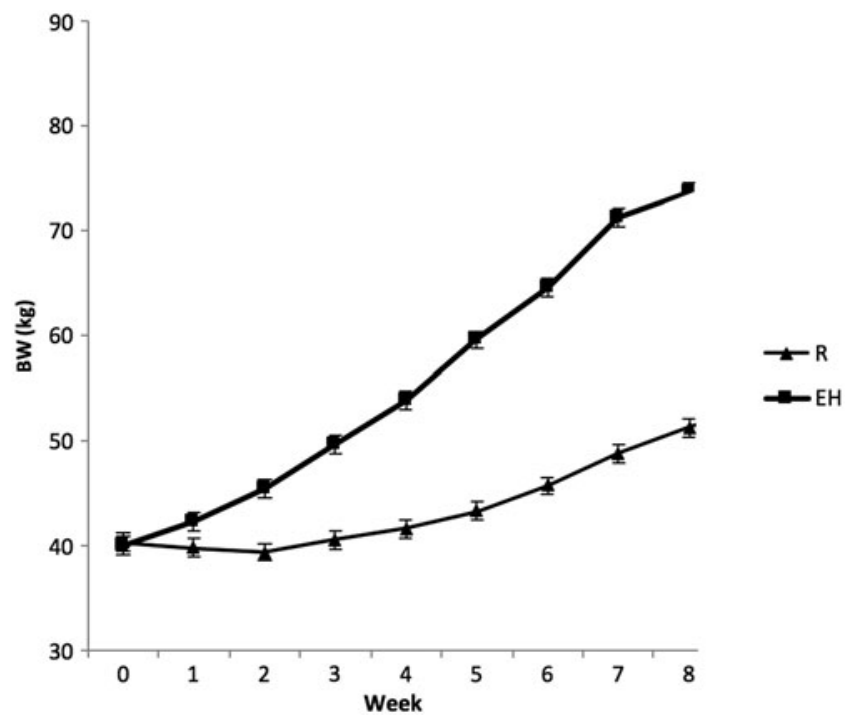

Figure 2 Weekly body weights through weaning of calves fed a low plane of nutrition ( $R$; triangles; $20 \%$ protein and $20 \%$ fat milk replacer) or a high plane of nutrition (EH; squares; $28 \%$ protein and $25 \%$ fat milk replacer). Significant treatment differences were observed during weeks 2 through 8 ( $P<0.01$; Geiger et al., 2016b).

(Figure 3; Geiger et al., 2016a, 2016b). Similar results were observed by Soberon and Van Amburgh (2017). It should be noted, however, that in this study, protein and fat content of the milk replacer was not altered between treatments. Visually, calves fed the HPN treatment experienced more complex PAR development into the MFP with clear secondary and tertiary branching of the MG epithelium, whereas calves fed less had a mammary PAR with little to no development (Figure 4).

When assessing cellular characteristics of the MG from calves fed a HPN, no differences were seen for the percentage of ER $\alpha$ positive cells (Figure 5), similar to the results found by Brown et al. (2005). However, Brown et al. (2005) did not assess the intensity of ER $\alpha \mathrm{mRNA}$ expression. In the present work, calves fed the HPN experienced almost a doubling of $E R \alpha$ protein expression intensity in ER $\alpha$-positive cells compared to calves fed less (Geiger et al., 2017). This is in direct opposition to results of tamoxifen-treated calves observed by Tucker et al. (2016b). One potential biological impact of these results may be that although calves fed the HPN did not have more ER $\alpha$-positive cells, the cells that were ER $\alpha$-positive were expressing a greater number of ERs and thus may be able to utilize estrogen with greater efficiency. In addition, the overall cellular proliferation rate of the mammary PAR was increased from $9.4 \%$ to $15.3 \%$ when a HPN was fed (Geiger et al., 2017; measured via Bromodeoxyuridine (BrdU) incorporation over a $24 \mathrm{~h}$ period), and in the terminal ductular units, percentage of epithelial cells proliferating increased from $12.7 \%$ to $22.9 \%$. Soberon and Van Amburgh (2017) did not assess cellular proliferation as a result of dietary modifications, whereas Brown et al. (2005) observed a reduction in Ki67 positive cells in the subtending ducts and terminal ductular units when a HPN was fed. Similar to that of Li and Capuco (2008), 895 genes

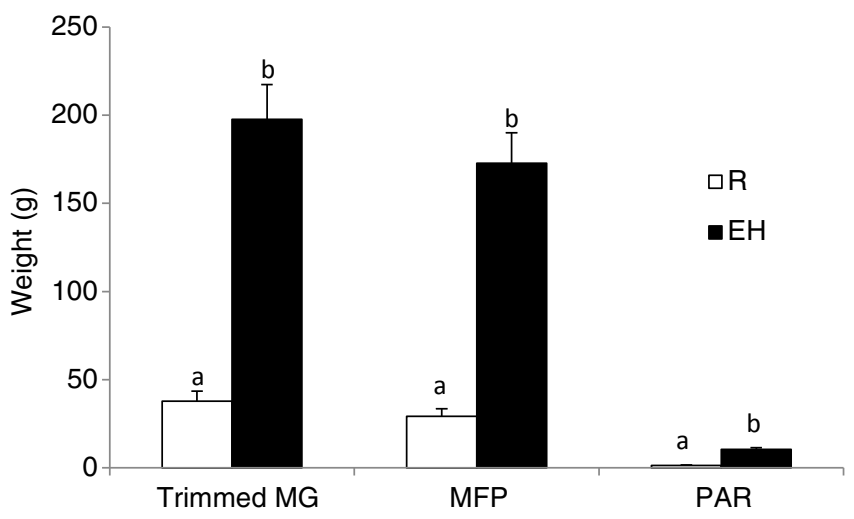

Figure 3 Mammary weights of Holstein heifer calves at weaning fed either a restricted diet (R; $20 \%$ protein and $20 \%$ fat milk replacer) or a HPN (EH; $28 \%$ protein and $25 \%$ fat milk replacer) pre-weaning. Superscripts within a given parameter $(a$ and $b)$ indicate treatment differences $(P<0.01)$. Trimmed $M G=$ whole trimmed mammary gland, $M F P=$ mammary fat pad, PAR = mammary parenchyma (Geiger et al., 2016a).

were up-regulated and 666 genes were down-regulated in the mammary PAR of calves fed a HPN. Gene classes impacted by feeding a HPN included nutrient metabolism/ absorption, cell movement, cellular proliferation, differentiation of cells and steroid/hormone biosynthesis.

From the discussed data, it is clear that the mammary PAR in early life is at the very least, more nutrient sensitive than suggested in earlier work. The extent of this sensitivity, however, is not fully understood and requires further investigation. Whether or not the MG itself is more estrogensensitive as a result of feeding a HPN requires more than one study be conducted. In the present study, when calves fed a HPN were given exogenous estrogen, mammary PAR mass accumulation was greatest compared to all other calves on trial. Calves fed less did not have a greater PAR mass when given exogenous estradiol (Figure 6). Similarly, although providing exogenous estrogen to calves fed a low plane of nutrition increased the cellular proliferation rate, calves fed a HPN and given exogenous estrogen experienced the highest rate of cellular proliferation (Geiger et al., 2017). Therefore, recent data may indicate that calves fed a HPN experience an increase in mammary PAR mass as a result of these dietary modifications, and this increase in MG development may in part be due to the fact that alterations to the mammary transcriptome create an environment within the MG that allows the organ to better utilize mammogenic stimuli, such as estrogen. It is doubtful that this would completely explain differences in future milk yield observed as a result of differing planes of nutrition in the pre-weaning period, but it may be an important piece of the puzzle.

\section{Other factors impacting the development of the bovine mammary gland}

The involvement of various other hormones and growth factors as they may relate to early MG development has been assessed. Examples of such factors include epidermal 

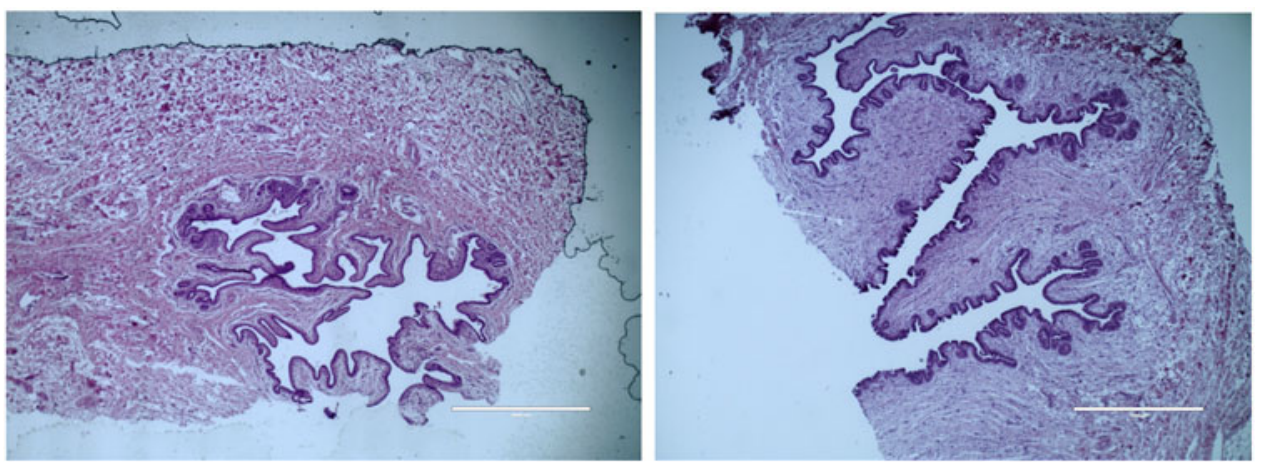

Figure 4 Histological depiction of MG parenchyma development differences between calves fed a low plane of nutrition (left; 20\% protein and 20\% fat milk replacer) or a high plane of nutrition (right; $28 \%$ protein and $25 \%$ fat milk replacer) at weaning. Images are of hematoxylin and eosin staining and are acquired with a $4 \times$ objective lens. Note a lack of coordination of branching in calves fed a low plane of nutrition, whereas calves fed a high plane of nutrition experienced secondary and tertiary branching of the parenchyma. The magnification bar equals $1000 \mu \mathrm{m}$ for the upper and middle panels (Geiger et al., $2016 \mathrm{a})$.
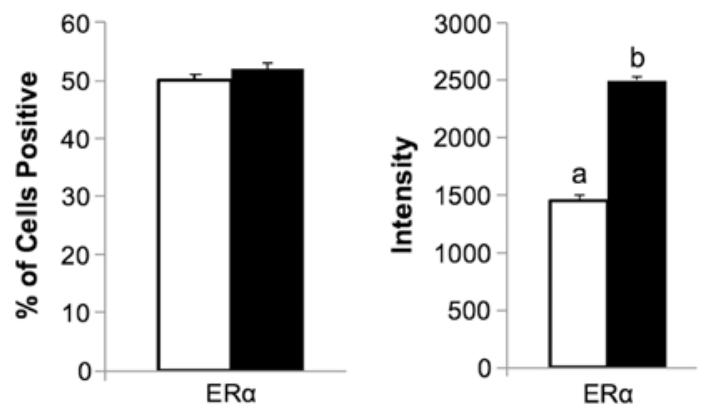

Figure 5 Percentage of cells expressing ER- $\alpha$ (left) and intensity of ER- $\alpha$ protein expression from ER- $\alpha$ positive cells (right) in calves fed a low plane of nutrition (white bars; $20 \%$ protein and $20 \%$ fat milk replacer) or a high plane of nutrition (black bars; $28 \%$ protein and $25 \%$ fat milk replacer). Note almost a doubling of ER- $\alpha$ expression intensity in calves fed a HPN (Geiger et al., 2017).

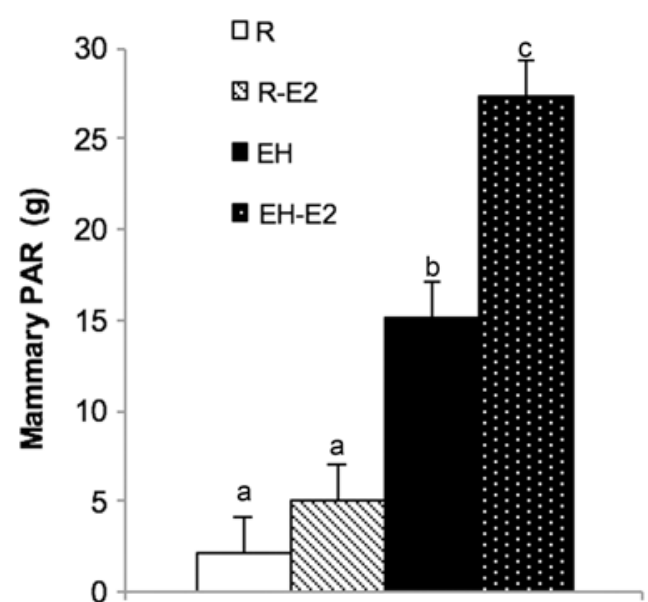

Figure 6 Mammary parenchyma (PAR) weights from calves fed either a low plane of nutrition ( $R$; white bars) or a high plane of nutrition (EH; black bars) with or without estrogen treatment post-weaning (R-E2 and EH-E2 indicate calves fed a low and high plane of nutrition and given estrogen for 2 week post-weaning; light cross bars and black bar with white dots, respectively). Superscripts above error bars $(a, b$ and $c)$ indicate treatment differences $(P<0.05)$. Note the significant increase in PAR growth in calves fed a HPN and given estrogen (Geiger et al., 2017). growth factor, prolactin, insulin, fibroblast growth factor, transforming growth factor $\beta$ and many others, and the success of understanding the role(s) these factors play in MG development has been variable. Recently, rodent studies (Coussens and Pollard, 2011; Need et al., 2014, Brady et al., 2016) have shown that a number of immune cells (macrophages, eosinophils and mast cells) congregate in the MG and may be involved in the regulation of ductal elongation and the development of the mammary PAR. To this point, data related to the involvement of immune cells in bovine MG development are limited, but our lab recently attempted to assess these populations in the neonatal bovine MG (Beaudry et al., 2016). Immune cells were not randomly distributed within the MG, but congregated rather near epithelial structures. The exact function of these cell populations in the bovine MG is still unknown, but if they are involved, it is likely that they play a role in the complicated cross-talk that coordinates the development of the MG.

Myoepithelial cells have also been hypothesized to play a role in the development of the pre-pubertal MG as early differentiation of myoepithelial cells as a result of an OVX procedure has been implicated in blocking the action of growth factors and hormones on the mammary epithelium (Ballagh et al., 2008; Safayi et al., 2012; Tucker et al., 2016a). Further investigation is needed to uncover the true role that this cell type may play in the development of the neonatal MG. Early work in our lab (Geiger et al., 2018) has shown that calves fed a HPN have myoepithelial cells that are morphologically different from calves fed a lower plane of nutrition. Calves fed a HPN had myoepithelial cells with a greater nuclear area and perimeter and had a greater number of neighboring myoepithelial cells in close proximity to them. Interestingly, calves subject to an OVX procedure appear to have myoepithelial cells with a smaller nuclear area compared to intact calves (Safayi et al., 2012), and calves injected with tamoxifen also experienced a reduced myoepithelial cell nuclear area (Tucker et al., 2016a). Additionally, tamoxifen treatment reduced the amount of neighbor contact between myoepithelial cells and decreased the myoepithelial cell nuclear perimeter (Tucker et al., 2016a). It is interesting to note that differences 
seen in the myoepithelial cell population as a result of feeding a HPN are opposite to that of the impact of either an OVX procedure or tamoxifen treatment, but the exact impact of these changes requires more investigation.

\section{Concluding remarks}

The study of the immature bovine MG is still in its infancy, but it is clear that interest in this area of mammary physiology is increasing. It is known that feeding dairy calves a HPN in early life results in increases in future milk yield. It is unlikely that improvements in the development of the MG deserve all credit for this, but it is undeniable that these improvements most likely play a key role. Just as the development of the neonatal MG is under the influence of a complicated network of cross-signaling between various factors, so too is the impact that early life nutrition has on the development of this extraordinary organ.

\section{Acknowledgements}

The authors acknowledge Land O' Lakes, Inc. (St. Paul, MN, USA) and Tom Earleywine (Land O' Lakes) for providing the milk replacer and support during this trial. We also acknowledge grant support from USDA-NIFA-AFRI (Washington, DC, USA), 2016-67015-24575, Impact of Pre-Weaning Nutrition on Endocrine Induction of Mammary Development in Dairy Heifers awarded to R. M. Akers and 2016-67011-24703 (pre-doctoral fellow-ship to A. J. Geiger).

(1) A. J. Geiger, 0000-0002-2486-0553

\section{Declaration of interests}

The author reports no conflict of interest. All data published in other journals by this author are appropriately referenced in the references section (Geiger et al., 2016a, 2016b, 2017).

The author has permission to reproduce all images from the original journal source.

\section{Ethics statement}

Work is approved by the appropriate parties.

\section{Software and data repository resources \\ Not applicable.}

\section{References}

Akers RM, McFadden TB, Purup S, Vestergaard M, Sejrsen K and Capuco AV 2000. Local IGF-I axis in peripubertal ruminant mammary development. Journal of Mammary Gland Biology and Neoplasia 5, 43-51.

Ballagh K, Korn N, Riggs L, Pratt SL, Dessuage F, Akers RM and Ellis S 2008. Hot topic: prepubertal ovariectomy alters the development of myoepithelial cells in the bovine mammary gland. Journal of Dairy Science 91, 2992-2995.

Beaudry KL, Parsons CLM, Ellis SE and Akers RM 2016. Localization and quantitation of macrophages, mast cells, and eosinophils in the developing bovine mammary gland. Journal of Dairy Science 99, 796-804.

Berry SD, Jobst PM, Ellis SE, Howard RD, Capuco AV and Akers RM 2003. Mammary epithelial proliferation and estrogen receptor alpha expression in prepubertal heifers: effects of ovariectomy and growth hormone. Journal of Dairy Science 86, 2098-2105.

Brady NJ, Chuntova P and Schwertfeger KL 2016. Macrophages: regulators of the inflammatory microenvironment during mammary gland development and breast cancer. Mediators in Inflammation 2016, 4549676.

Brown EG, Vandehaar MJ, Daniels KM, Liesman JS, Chapin LT, Forrest JW, Akers RM, Pearson RE and Nielsen MS 2005. Effect of increasing energy and protein intake on mammary development in heifer calves. Journal of Dairy Science 88, 595-603.

Capuco AV and Akers RM 2010. Management and environmental issues influences on mammary gland development and milk production. In Managing the prenatal environment to enhance livestock productivity (ed. PL Greenwood, AW Bell, PE Vercoe and GJ Viljoen), pp. 259-292. Springer Science+Business Media B. V., Dordrecht, The Netherlands.

Capuco AV, Ellis S, Wood DL, Akers RM and Garrett W 2002. Postnatal mammary ductal growth: three-dimensional imaging of cell proliferation, effects of estrogen treatment, and expression of steroid receptors in prepubertal calves. Tissue \& Cell 34, 143-154.

Coussens LM and Pollard JW 2011. Leukocytes in mammary development and cancer. Cold Spring Harbor Perspectives in Biology 3, a003285. doi: 10.1101/ cshperspect.a003285. Access: 25, April 2018.

Ellis SE, McFadden TB and Akers RM 1998. Prepubertal ovine mammary development is unaffected by ovariectomy. Domestic Animal Endocrinology 15, 217-225.

Geiger AJ, Parsons CLM and Akers RM 2016a. Feeding a higher plane of nutrition and providing exogenous estrogen increases mammary development in Holstein heifer calves. Journal of Dairy Science 99, 7642-7653.

Geiger AJ, Parsons CLM, James RE and Akers RM 2016b. Growth, intake, and health of Holstein heifer calves fed an enhanced preweaning diet with or without postweaning exogenous estrogen. Journal of Dairy Science 99, 3995-4004.

Geiger AJ, Parsons CLM and Akers RM 2017. Feeding an enhanced diet to Holstein heifers during the preweaning period alters steroid receptor expression and increases cellular proliferation. Journal of Dairy Science 100, 8534-8543.

Geiger AJ, Parsons CLM and Akers RM 2018. The impact of pre-weaning plane of nutrition on the myoepithelial cell population within the immature bovine mammary parenchyma. Journal of Dairy Science 101 (Suppl. 2), 380-381.

Khan MA, Weary DM and von Keyserlingk MA 2011. Invited review: effects of milk ration on solid feed intake, weaning, and performance in dairy heifers. Journal of Dairy Science 94, 1071-1081.

Li RW and Capuco AV 2008. Canonical pathways and networks regulated by estrogen in the bovine mammary gland. Functional \& Integrative Genomics 8, 55-68.

Meyer MJ, Capuco AV, Ross DA, Lintault LM and Van Amburgh ME 2006a. Developmental and nutritional regulation of the prepubertal bovine mammary gland: II. Epithelial cell proliferation, parenchymal accretion rate, and allometric growth. Journal of Dairy Science 89, 4298-4304.

Meyer MJ, Capuco AV, Ross DA, Lintault LM and Van Amburgh ME 2006b. Developmental and nutritional regulation of the prepubertal heifer mammary gland: I. Parenchyma and fat pad mass and composition. Journal of Dairy Science 89, 4289-4297.

Need EF, Atashgaran V, Ingman WV and Dasari P 2014. Hormonal regulation of the immune microenvironment in the mammary gland. Journal of Mammary Gland Biology and Neoplasia 19, 229-239.

Purup S, Sejrsen K and Akers RM 1995. Effect of bovine GH and ovariectomy on mammary tissue sensitivity to IGF-I in prepubertal heifers. Journal of Endocrinology 144, 153-158.

Purup S, Sejrsen K, Foldager J and Akers RM 1993. Effect of exogenous bovine growth hormone and ovariectomy on prepubertal mammary growth, serum hormones and acute in-vitro proliferative response of mammary explants from Holstein heifers. Journal of Endocrinology 139, 19-26.

Purup S, Vestergaard M and Sejrsen K 2000. Involvement of growth factors in the regulation of pubertal mammary growth in cattle. Advances in Experimental Medicine and Biology 480, 27-43.

Safayi S, Korn N, Bertram A, Akers RM, Capuco AV, Pratt SL and Ellis SE 2012. Myoepithelial cell differentiation markers in prepubertal bovine mammary gland: effect of ovariectomy. Journal of Dairy Science 95, 2965-2976.

Sejrsen K 1994. Relationships between nutrition, puberty and mammary development in cattle. The Proceedings of the Nutrition Society 53, 103-111. 


\section{Geiger}

Sejrsen K and Purup S 1997. Influence of prepubertal feeding level on milk yield potential of dairy heifers: a review. Journal of Animal Science 75, 828-835. Soberon F, Raffrenato E, Everett RW and Van Amburgh ME 2012. Preweaning milk replacer intake and effects on long-term productivity of dairy calves. Journal of Dairy Science 95, 783-793.

Soberon $F$ and Van Amburgh ME 2017. Effects of preweaning nutrient intake in the developing mammary parenchymal tissue. Journal of Dairy Science 100 5390-5399

Tucker HA 2000. Hormones, mammary growth, and lactation: a 41 -year perspective. Journal of Dairy Science 83, 84-884.

Tucker HLM, Beaudry KL, Parsons CLM, Ellis SE and Akers RM 2016a. Impaired mammary development in tamoxifen-treated prepubertal heifers is associated with altered development and morphology of myoepithelial cells. Journal of Dairy Science 99, 10093-10101.

Tucker HLM, Parsons CLM, Ellis S,Rhoads ML and Akers RM 2016b. Tamoxifen impairs prepubertal mammary development and alters expression of estrogen receptor $\alpha$ (ESR1) and progesterone receptors (PGR). Domestic Animal Endocrinology 54, 95-105.
Velayudhan $\mathrm{BT}$, Huderson $\mathrm{BP}$, Ellis $\mathrm{SE}$, Parsons $\mathrm{CL}$, Hovey $\mathrm{RC}$, Rowson $\mathrm{AR}$ and Akers RM 2015. Ovariectomy in young prepubertal dairy heifers causes complete suppression of mammary progesterone receptors. Domestic Animal Endocrinology 51, 8-18.

Velayudhan BT, Huderson BP, McGilliard ML, Jiang H, Ellis SE and Akers RM 2012. Effect of staged ovariectomy on measures of mammary growth and development in prepubertal dairy heifers. Animal: An International Journal of Animal Bioscience 6, 941-951.

Vestergaard MS, Purup J, Frystyhk P, Løvendahl MT, So- Rensen P, Riis M, Flint DJ and Sejrsen K 2003. Effects of growth hormone and feeding level on endocrine measurements, hormone receptors, muscle growth and performance of prepubertal heifers. Journal of Animal Science 81, 2189-2198.

Woodward TL, Beal WE and Akers RM 1993. Cell interactions in initiation of mammary epithelial proliferation by oestradiol and progesterone in prepubertal heifers. Journal of Endocrinology 136, 149-157.

Zanton GI and Heinrichs AJ 2005. Meta-analysis to assess effect of prepubertal average daily gain of Holstein heifers on first-lactation production. Journal of Dairy Science 88, 3860-3867. 